a well-developed, intelligent girl, with a family and personal history remarkably free from any neurotic or other complaints. Her affection dated from 1883. It had gradually supervened, and culminated in a most distressing state of things, the head being so extremely rotated as to bring the left ear with sudden jerks into a line with the sternum. 'This took place every few seconds, not altogether ceasing, although less violent during sleep. With regard to treatment, she had been dosed with drugs innumerable, galvanised, blistered, her tonsils removed, and the galvanocautery applied to the back of the throat, without beneficial results. I sent the case to St. Thomas's Home, and there, with Drs. Elmunds and Sutton's valuable assistance, had little difficulty in finding the spinal accessory nerve emerging from the onter border of the sternomastoid muscle. Taking the nerve as a guide, I tunnelled through the muscle for some distance, using a moderate amount of traction on the nerve, but avoiding injury as far as possible to the muscle. This done I placed a loop of silver wire round the nerve as high as I could reach, just twisting the ends to ensure slight compression. The wound was treated in the usual way, the ends of the loop protruding. On recovering from the chloroform the spasms had entirely ceased. The wound subsequently healed by first intention, without pain or discomfort in any way. After a fortnight the patient returned to her home in Kent. At the end of three months she visited me, still without the smallest return of the spasms, and much improved in health. Nothing seemed amiss with the sterno-mastoid or trapezius; she could rotate her head, and retain it in any position. : cut off the ends of the loop as close as possible, so as to allow the skin to grow over them. I have not seen the patient since, but learn from time to time from Dr. Sutton that she remains perfectly free from a return of her troubles. I append a letter lately received, indicating her present condition.

"Chesley, Nervington, April 5th, 1890.

"Dear Mr. Collier,-I thought you might like to know how I am mrogressing. Am pleased to say I am feeling quite well, and have just three weeks. I have also been to several dances this winter. So you see I am much stronerer, and can keep upright.

"Mr. Collier." "Believe me, yours sincerely,

New Cavendish-street, W.

\section{A a}

\section{HOSPITAL PRACTICE, BRITISH AND FOREIGN.}

Nulla autem est alia pro certo noscendi via, nisi quamplurimas et morborum et dissectionum historias, tum aliorum tum proprias collectas horum et dissectionum historias, tum aliorum tum proprias collectas lib. iv. Proœmium.

\section{ST. THOMAS'S HOSPITAL.}

INYERSION OF THE UTERUS, DUE TO A LARGE POLYPUS ; SUPERFICIAL NECROSIS OF BOTH UTERUS AND TUMOUR; SUDDEN EXTRUSION OF THE ENTIRE MASS THROUGH THE VULVA; REMOVAL OF TUMOUR, WITH SURSEQUENT REDUCTION OF THE INVERSION; REMARKS.

(Under the care of Dr. CULLINGworTH.)

THIs is an excellent example of the reduction of oldstanding inversion of the uterus by the elastic repositor, after the removal of a fibroid tumour on which the inversion depended. The account is given at some length because of the unusual character of the case. For references to the literature on the subject we refer our readers to the remarks appended to it.

A married woman, aged forty-five, was admitted to St. Thomas's Hospital on April 9th, 1890. She was extremely blanched and in a state of collapse, the pulse at rthe wrist being scarcely perceptible. Protruding from the vulva was a large solid mass, ulcerated and suppurating over its whole surface, and giving off a highly offensive odour. The tumour, vulva, and inner parts of the thighs, as well as the clothing, were covered with discharge mixed with blood. The account was that sixteen months previously she was told she had cancer of the womb, that she gad had a foul discharge ever since, and that three days ago, whilst walking in the street with a child in her arms, she was suddenly seized with severe pain low down in the abdomen, felt something force its way out of her body, found herself drenched with blood, became faint and giddy, and had to be taken home in a cab. For some months she had been aware that there was a lump, for she had been able both to feel it and see it; but until this occasion it had never become completely extruded. A doctor endea. voured to replace the procident mass, but without success. During the three days that had since elapsed there had been continuous loss of blood. The resident officer on duty (Mr. Low), after washing the extruded mass with a solution of mercuric perchloride, returned it within the vulva, and subsequently admitted her.

On admission, her temperature was subnormal, $96^{\circ}$; her pulse 136, very small and feeble. Next day she had rallied somewhat, and the following additional particulars of her history were obtained. The catamenia commenced at the age of twelve; the patient had married at twenty, and had borne five children, of whom the eldest was twenty-five years of age, the youngest nineteen. She had had no miscarriages. Her present illness began three years ago, with irregular and profuse hæmorrhage. She became weak and pale after the attacks, and frequently suffered from pain around the loins and down the legs. About eighteen months ago there commenced to be a continuous watery, fetid, blood-stained discharge. About the same time the patient began to suffer from pains, like labour pains, and a constant sensation as of "something wanting to come away." She was examined by her own doctor, who told her there was something hard in the womb that ought not to be there. Shortly before Christmas, 1888, she applied for admission at a hospital for women. The doctor who examined her said that she was suffering from cancer. She was taken to the Middlesex Hospital, but left of her own accord in three days, before any examination had been made.

Dr. Cullingworth saw and examined the patient on the day following her admission. Finding the mass in the vagina smooth, comparatively soft, and lobulated, he placed ber in the dorsal position on the operating table, and, seizing the tumour with two volsella, drew it outside the vulva for inspection. It presented the appearance of an oblong tumour, the surface of which was ulcerated and covered with an extremely fetid purulent discharge. At its base of attachment it seemed to be continuous all round with the walls of the vagina, without any intervening groove or sulcus. The upper portion of the mass was somewhat softer, and of a more livid hue than the lower, the division between the two being marked by an ill-defined and very shallow groove which ran all around the mass, at about the middle of its length. A nodule of firm consistence projected from the lower end of the mass on its left side. This nodule had a diameter of five-eighths of an inch. The diagnosis was: Complete inversion of the uterus, with a fibroid polypus attached by a broad base to its fundus, the exposed surface of both uterus and tumour being in a state of superficial necrosis. On bimanual examination, with one finger in the rectum, the body of the uterus was found to be absent from its normal situation. A sound introduced into the bladder could be felt distinctly by the finger in the rectum inmediately above the vaginal roof. Passing from the vaginal roof upwards and outwards on each side was a thick tense band, evidently consisting of the broad ligament put greatly on the stretch. The roof of the vagina was not depressed. By means of a scalpel a transverse incision was there and then made across the tumour, about half an inch below the shallow groove already mentioned, and, as the interior was found not to be very vascular, the incision was carried completely through it, and the greater part of it thus re moved. The outer covering of the remaining half-inch of the growth was now peeled up, and the base enucleated from the fundus uteri by means of the fingers. At its centre a band of tissue less than half an inch in diameter passed from the growth directly into the fundus; this stalk was divided with scissors, and the capsule which had been peeled off from the base of a tumour was also cut away. The inverted uterus was now left free from the growth. To check the oozing from the raw surface four silk sutures were passed beneath it and tied, so as to fold it upon itself. This at once stopped the bleeding. The vagina was then douched with a weak solution of corrosive sublimate. The uterus, still inverted, was replaced within 
the vagina, an iodoform tampon placed against the sutured wound, aud the patient sent back to bed. The mass removed had, on section, the usual appearance of a fibroid tumour of the uterus. Its length was four inches, its circumference at the broadest part eight inches, and the diameter of its base two inches and $a$ half. The necrotic process had not extended into the interior of the growth. In the evening of the following day the patient's temperature rose to $103^{\circ}$; and, on making a vaginal examination, Mr. Boycott, the resident accoucheur, found the fundus uteri tense, swollen, and tender, the stitches being quite concealed from view by the swelling. He thereupon removed one of the stitches, with the result of setting free a quantity of serum and affording great relief to the tension. The temperature, however, remained high, frequent shiverings occurred, and though there was little or no pain, the patient's tongue became dry and she looked very weak and ill.

On the fourth day after the operation, April 13th, the remaining sutures were removed. No bleeding took place from the raw surface, which was now exposed. Thinking it doubtful whether the uterus would assume a healthy condition so long as its circulation was impeded by its abnormal position, Dr. Cullingworth determined to attempt its reduction. With this object continuous elastic pressure was applied by means of Aveling's repositor, iodoform gauze being packed around the uterus, and between the raw surface of the fundus and the cup of the instrument. The following morning the temperature had become reduced to $100^{\circ} 4^{\circ}$. The patient had not slept much, but did not complain of much pain. At 10 A.M. the repositor was readjusted with fresh packing, and again at 4 P.M, this time without packing. On the 15th there was a good deal of bloodstained discharge, and some clots were passed. The patient also complained of pais. The repositor, which had slipped a little, was now removed, having been in position for forty-eight hours. Dr. Cullingworth now determined to wait before again attempting to reduce the inversion, in order to ascertain whether, by rest and frequent douching, the condition of the uterus would not improve. The result was extremely satisfactory. The foul discharge, at first profuse, gradually diminished and ultimately ceased; the uterus became less swollen, its mucous membrane gradually assumed a healthy aspect, and the wound on the fundus healed. At the end of April a shallow sulcus could be felt around the neck of the uterus.

On May 13th, twenty-eight days after the removal of the repositor, the instrument was again applied, the uterus being packed round with iodoform gauze. It was read justed the following day without any packing, and, after being kept on for five days, was removed, the patient beginning to feel discomfort from the loaded state of the bowels. The condition after the removal of the instrument was as follows. The vaginal mucous membrane was somewhat soft, swollen, and tender. The body of the uterus still projected into the vagina, but was high up, and around the upper part of the inverted organ there could be felt a deep, narrow sulcus, in parts an inch in depth, in other parts an inch and $a$ half. The outer wall of the sulcus consisted of a broad, tense band, completely encircling, and, as it were, grasping the uterus. The fundus projected an inch below the mouth of the sulcus; as the cup was removed, a few drops of thin yellowish serum escaped, quite free from offensive odour.

A week was now allowed to elapse, and on May 25th, the bowels having been well cleared, the repositor was reintroduced, without any packing, a smaller cup being used this time than on the two previous occasions. The uterus had descended a little lower than when the instrument was last removed, occupying now much the same position that it did five weeks earlier, after the first application. For the first thirty hours the patient suffered little or no pain after that time she complained of a good deal of pressure but at no time did she experience any sudden pain or shock. The instrument was removed at 3 P.M. on the 27 th, when it had been in position for fifty hours. The removal was easily effected by tilting the cup on one side, passing a finger over its rim, and depressing it, whilst traction was made on the stem. The inversion had become completely reduced. The cervix was sufficiently dilated to admit two fingers. The length of the uterine canal was two inches and a half; the distance from the vulva to the os uteri, three inches and a half. The fundus was tender both externally (as ascertained by the hand during bimanual examination) and internally (as ascertained by the sound). It was impossible to fix the precise moment when the uterus went back, there having been no symptom to indicate it. Reduction had certainly not taken place at the end of the first twenty-four hours; after that no vaginal examination had been made. Little or no discharge followed the removal of the instrument, and next day the patient, though stiff from lying in one position, and somewhat weak, expressed herself as feeling perfectly well. In a day or two she wast moving about the ward, and on June 7 th she went home, free from discharge of any kind, with the uterus in its natural position and no longer even tender to the touch, and with her general health greatly improved and in a farr way for becoming completely restored.

Remarks by Dr. CullingworTH.-Chronic inversion of the uterus is, under all circumstances, a rare displacement, and of the cases that do occur only a very small number is due to causes unconnected with parturition. The most frequent of such causes is intra-uterine polypus. For the most part, the polypi that produce this displacement during their expulsion from the uterine cavity are attached by a broad base-ur, in other words, are sessile. The consequence of this is that the separation between the inverted uterus and the tumour attached to its fundus is often ill defined, and the whole mass presents the appearance of a single tumour. Hence it is by no means surprising that amputation of the inverted uterus has been performed several times under the mistaken impression that a large polypus was being removed. The difficulty of diagnosis is well illustrated in a case recently recorded by Dr. Horrocks, in which the tumour was at first thought to be a polypus, was afterwards made out to be an inverted uterus, and treated as such, and was finally discovered to be a combination of the two. ${ }^{1}$ It was chiefly owing to my recollection of this case that I was led to suspect at once the true state of matters in mine, though the furrow marking the line of division was so slight as to be difficult to demonstrate to the bystanders, and the slough ing condition of the mucous membrane covering both the inverted uterus and the polypus introduced an additional element of confusion. With regard to the treatment adopted, it will be observed that the tunour was not at first removed in its entirety. In a case where this was attempted a portion of the fundus was inadvertently cut away with the tumour. ${ }^{2}$ It seems preferable, therefore, if the knife be used or the écraseur (the days of which, so far as the removal of uterine tumours is concerned, are, $I$ believe numbered), to leave a portion of the growth to be removed separately by the slower but safer process of enucleation. The slight hæmorrhage that took place from the raw surface left after the tumour was separated was easily arrested by folding the surface in wards upon itself, and maintaining it in this position by a few temporary sutures. The question as to the best method of dealing with the inverted uterus was a more difficult one. Under ordinary circumstances, the accepted treatment of chronic inversion of the uterus, at any rate in this country and in America, is reduction by sustained elastic pressure, however long. the displacement may have lasted. Amputation is now justly regarded as a last resonrce, only to be resorted to after repeated and prolonged efforts at gradual reposition have proved unavailing. Doubts have indeed been expressed whether amputation (which, curiously enough, seems to be still the recognised mode of treatment in Germany when taxis has failed) is ever really justified. That the more unpromising cases may with perseverance be rectified with out mutilation is abundantly proved by the many instances of success to be found in the medical literature of England and America. Encouraged by the knowledge of what others had accomplished, I determined not to sacrifice the uterus in this case until I had satisfied myself that reposition was. inpossible. At the same time I could not but realise that the conditions were extremely unfavourable. The first attempt at replacement, as might have been anticipated, failed; but by allowing the uterus time to get into a healthy condition before reapplying the apparatus, complete success was eventually attained. The instances on record of non-puerperal inversion of the uterus successfully treated by sustained pressure are as yet few in number. The earliest, so far as I have been able to ascertain, was reported by Dr. Albert F. Field (now of Ramsgate)

1 Trans. Obst. Soc., Lond., vol. xxx., 1888, p. 196 2 W. T. Lusk, Trans. Obst. Soc. of New York, vol. i., 1879, n. 401.. 
Wn the year 1872.3 The case was under the care of Dr. Greenhalgh at St. Bartholomew's Hospital, the form of elastic pressure which he used being an air-bag. Another oase is related, in a later volume of the same series of Reports, by Dr. Matthews Duncan, ${ }^{4}$ who employed a straight cup-and-stem repositor, attached to a T-bandage by elastic straps. Dr. T. G. Thomas of New York effected reposition in a case that came under his care by means of a Byrne's repositor;" while Herman, in a case reported to the $\mathrm{Ob}$ stetrical Society of London, ${ }^{6}$ in which, unfortunately, the treatment was interrupted by the patient's death owing to progressive gangrene of the inverted uterus, employed the sigmoid repositor of Dr. Aveling. In fact, since Tyler Smith in this country, and Jas. P. White in America, first suggested and carried out the principle of treatment by sustained pressure, many different methods have been em mloyed, each being in some respects an improvement on its predecessors. The instrument of $\mathrm{Dr}$. Aveling is, in my opinion, the best and most efficient that has yet been de rised. ${ }^{7}$ Dr. C. C. Lee of New York has described two cases in which, after the tumour had been wholly or in part removed, sustained solid pressure was kept up for three or rour weeks by astringent tampons introduced into the vagina and changed day by day, the result being in each instance successful. 8

It is only fair to say that Dr. Lee himself does not appear to attribute the reduction to the pressure exercised by the tampons; he speaks of it as having occurred spontaneously. Whether this was so or not in the two instances in question it seems certain that spontaneous reduction of an inverted aterus may take place. Several apparently well-authenticated examples of this fortunate occurrence are cited by Dr. R. Barnes, ${ }^{9}$ and by Dr. R. P. Harris of Philadelphia. ${ }^{10}$

\section{SOUTH DEVON AND EAST CORNWALL HOSPITAL, PLYMOUTH.}

ACUTE OVARITIS, FOLLOWED BY SUPPURATIVE PERITONITIS; DEATH; REMARKS.

(Under the care of Dr. Clay.)

ACUTE ovARITIS running on to suppuration is fortunately not a disease which often presents itself for treatment in the wards of our hospitals, and our literature on the subject is not extensive. This case is an example, in which, after a chill, suppuration in the right ovary followed, and the patient died from acute peritonitis. The chief points in the clinical history are indicated in the remarks. For the following report we are indebted to $\mathrm{Mr}$. W. Gifford Nash, house surgeon.

G. B-, aged twenty-three, unmarried, began to feel ill on Saturday, March 15th, and on the evening of the 16 th her temperature was $102^{\circ}$. She complained of nausea and headache, but denied the presence of any other pain. She was given bismuth, sal volatile, and bromide of potassium, which gave great relief. On the $17 \mathrm{th}$ she insisted on getting up, as she felt quite well. During that night she telt cold and shivered. On Tuesday morning, March 18th, she got up, but, feeling sick, returned to bed. In the evening she said that she had felt sick all day, but had only vomited once; she had a headache, but no other pain. It was about the proper time for her period, but this had not appeared. She said that lately she had not been very regular. The pulse was 120 ; temperature $1042^{\circ}$. Tongue furred. A systolic bruit was heard at the cardiac apex and pulmonary base. She passed a very bad night, was constantly sick, and her bowels acted three times. The vomit was bilious, and the motions loose and dark. On Wednesday, the $19 \mathrm{th}$, at 10 A.M., her temperature was $101 \cdot 6^{\circ}$; pulse 132 . Her features were pinched and blanched, and eyes very much sunken; abdomen natural ; spleen not enlarged; no spots. At 3 P. M. she complained of a shooting pain on the right side of the abdomen, and a distinct, tender, rounded

3 St. Bartholomew's Hospital Reports, vol. viii., 1872, p. 133. 4 Ibid., vol. xiv., 1878 , p. 97.

5 Trans. New York Obstetr. Soc., vol. i., 1879, p. 458.

6 Trans. Obstetric Soc, of Yond., vol. xxx., 1888, p. 226

7 Ibill., vol. xx., 1878, p. 126 ; also, Lecture on Inversion of the Uterus, Brit. Med. Journ., vol. i., 1886, p. 475.

8 American Journal of Obstetrics, vol. xxi., 1888, p. 616

9 Clinical History of the Diseases of Women, second edition, p. 723 Eondon: 1878. $\quad$ 10 Amer. Journ. Med. Sciences, Jan. 1880, p. 141. welling was felt in the right iliac region. The bowels had acted six times since 10 A.M. Ten minims of laudanum, with half an ounce of brandy, were ordered every four hours, and linseed poultices to the abdomen. At 9 P.M. the temperature was $1044^{\circ}$. Five grains of quinine, with three ounces of beef-tea and ten minims of laudanum, were given as an enema, and repeated twice in the night.

On Thursday, March 20th, she was worse, having passed a bad night. Her tongue was red at the tip. Abdomen slightly distended, so that the swelling in the right iliac region could not be felt. Temperature $103^{\circ}$; pulse 132 ; urine was acid, sp. gr. 1025, and contained one-third of albumen. Under the microscope were seen hyaline and granular casts and epithelial cells. Half an ounce of brandy was ordered to be given every two hours, an ounce of milk with an equal quantity of hot water every hour, and a sixth of a grain morphia suppository every four hours, and a soft rectal tube to be passed occasionally.

In the afternoon the respirations were very slow, only four or five in a minute; pulse was 124 . At 5.30 P M. she refused brandy, so champagne was substituted. She vomited at 6.45 and 1030 P.M. At 7 P.M. the abdomen was smeared with equal parts of belladonna ointment and mercury ointment.

On Friday, March 2lst, shewas clearer mentally. At $6 \mathrm{~A}$ M. the temperature was $1046^{\circ}$; pulse 144 . Tongue dry and red at the tip. Breathing still slow, deep, and sighing. No pain; no more sickness; no flatus through rectal tube. Urine : $13 \mathrm{oz}$. in twenty-four hours; acid; sp. gr. 1020; contained one-sixth of albumen and numerous hyaline and a few epithelial casts. She gradually got worse through the day, and died at 1.15 A. M. on March 22 nd.

Necropsy, sixteen hours after death. - The abdomen, which was slightly distended, was alone opened. The omentum and intestines were matted together with flakes of recent lymph. The intestines were distended, and contained a large quantity of fluid. There was very little injection of peritoneum in the upper part of the peritoneal cavity. In the flanks, in the right iliac fossa, and in the pelvis was a large quantity of purulent fluid and recent lymph. The peritoneum lining the pelvis was much in. jected, especially that covering the Fallopian tubes and ovaries. The ovaries lay low down in the pelvis, apparently pushed down by the distended intestine. The bladder was empty and natural, the vagina contained some brownish detritus, the uterus was small and virginal, and the cervical canal contained a little clear mucus. The uterine mucous membrane was pale. The Fallopian tubes were much congested, coated with Iymph and surrounded by pus. The right ovary was enlarged to the size of a bantam's egg, coated with lymph, very dark in colour and soft in consistence. On section the surfaces were purple, with scattered yellow spots of commencing suppuration. The left ovary was surrounded by lymph, and was slightly enlarged. The cacum and vermiform appendix were quite natural. Both kidneys were a little enlarged, pale, and rather soft; capsules were not adherent.

Remarles by Mr. NASH. - This illness at its onset was very indefinite, the only symptoms being nausea, headache, and feverishness, and it was quite uncertain what it was until the fifth day from its commencement, when the patient had a little abdominal pain, and the swelling was felt. Pelvic peritonitis due to a chill was then diagnosed. The cardiac murmur and albuminuria, with presence of renal casts, were unfavourable symptoms. This illness occurred during an epidemic of influenza and scarlet fever, and when numerous cases of tonsillitis were occurring in the hospital, and it was suggested whether any septic mischief was at the bottom of it. There appears, however, to be sufficient cause to account for it otherwise-viz., the fatigue of her first three weeks' hard work, and a serious chill when her menstrual period was due. It afterwards transpired that at the menstrual period, a month before this illness, she fainted, and suffered great pelvic pain. It was unfortunate that there was no pain pointing to the onset of ovaritis, so that local applications might have been applied earlier. It is also, perhaps, to be regretted that laparotomy was not performed, the inflamed ovary renoved, and the peritoneal cavity washed out. There was nothing to indicate the presence of the inflamed ovary until sixty hours before death, and for the last forty-eight hours she was so extremely collapsed that it is doubtful whether she would have stood the shock of any operation 